$\int_{\mathcal{G}}^{\text {Semantics \& Pragmatics Volume 9, Article 18: 1-11, } 2016}$

\title{
A problem for Predicativism not solved by Predicativism
}

\author{
Anders J. Schoubye \\ University of Edinburgh
}

Submitted 2015-12-16 / First decision 2016-02-02 / Revision received 2016-02-07 / Accepted 2016-02-15 / Final version received 2016-02-16 / Published 2016-04-27

\begin{abstract}
Hawthorne \& Manley 2012 observe that there is a clear contrast between (1) and (2):

(1) In every race, the colt won.

(2) In every race, John won.

Whereas the colt in (1) has a co-varying reading, John in (2) does not. This is a problem for the so-called Predicativist view of names defended by e.g., Elbourne 2005, Matushansky 2006, 2008, Izumi 2013, and Fara 2015a,b,c. In a recent response to Hawthorne and Manley, Fara argues that this contrast is not only not a problem for her view, but it is in fact predicted by it. In other words, the existence of this contrast, according to Fara, provides an argument in favor of Predicativism. In this short discussion note, I show that Fara's response has significant shortcomings and that the contrast between (1) and (2) remains a considerable problem for the Predicativist view of names.
\end{abstract}

Keywords: names, definite descriptions, domain restriction, binding

The-Predicativism is the view that names uniformly have predicate semantic values. Specifically, names are count nouns. Moreover, when a bare singular name occurs in argument position of a predicate, the name is assumed to be the argument of a phonologically null (i.e., unprononced) definite determiner. ${ }^{1}$ In short, according to The-Predicativism, the LF of the sentence in (1) is (1a).

1 Proponents of The-Predicativism include Geurts 1997, Elbourne 2005, Matushansky 2006, 2008, Izumi 2013, Fara 2011, 2015a,b,c. For a clear and in-depth statement of the view, see Fara 2015C.

(C) 2016 A. J. Schoubye

This is an open-access article distributed under the terms of a Creative Commons Attribution License (http://creativecommons.org/licenses/by/3.o/). 
A. J. Schoubye

(1) John is a philosopher.

a. [s [DP $\emptyset_{\text {the }}$ John] [vp is a philosopher]]

In a recent paper, Fara 2015a responds to a problem for The-Predicativism that was raised by Hawthorne \& Manley (2012: 235). Hawthorne and Manley observe that there is a clear contrast between the two sentences below.

(2) In every race, the colt won.

(3) In every race, John won.

Whereas (2) has a reading where the determiner phrase the colt co-varies with the quantifier, and so can refer to different colts for each race, such a reading is not available for (3). This looks like a problem for The-Predicativism. The only difference between (2) and (3), according to their analysis, is that the definite determiner in (3) is unpronounced, but whether the determiner is pronounced or unpronounced should not intuitively affect what readings are available.

In response to this putative problem, Fara argues that when The-Predicativism is combined with a plausible analysis of the syntax and semantics of nominal phrases, the contrast between (2) and (3) is actually predicted by ThePredicativism.

First, based on observations of the distribution of names in a number of syntactic environments, Fara (2015a) proposes the following generalization about the distribution of the phonologically null the. ${ }^{2}$

Where ' $\emptyset_{\text {the }}$ ': When a name occurs in a definite description, the definite article must be unpronounced when the name is its structural sister, unless the definite article is stressed. (Fara 2015a: 367)

This generalization is predictive. It accounts for when and where the must be unpronounced. For example, assuming that The-Predicativism is true, it correctly predicts that (4)-(7) are grammatical and that (8) is not.

(4) $\emptyset_{\text {the }}$ Alfred is Scandinavian.

(5) The Alfred we met last night is Scandinavian.

(6) The old Alfred is Scandinavian.

2 The arguments in favor of this descriptive generalization are intricate and extensive, so for reasons of space, I do not reproduce them here, however see e.g., Fara 2015c: 90-97 and Fara 2015a: 365-368 for details. 
A problem for Predicativism not solved by Predicativism

(7) THE Alfred is Scandinavian.

(8) *The Alfred is Scandinavian.

Now, consider this minimal pair.

(2) In every race, John won.

(9) In every race, the John won.

The relevant observation about (2) and (3) holds for (2) and (9) too. The sentence in (9) seems to have a reading where the John refers to different individuals relative to different races, whereas (2) does not. But, as Fara herself points out, the sentence in (9) thus appears to be a counterexample to the above generalization. In (9), the determiner has a (bare) name as its structural sister and it is not stressed, hence the generalization predicts that the determiner should not be pronounced - yet it is. In conclusion, the generalization looks false.

To rebut this conclusion, Fara appeals to a recent analysis of the syntax and semantics of nominal phrases. She writes (Fara 2015a: 368):

One way to account for the covariation in [(9)] is to posit a bindable variable as part of a nominal restriction on the name. This is what Jason Stanley and Zoltán Szabó do as part of their argument that quantifier domain restriction is to be accounted for as nominal restriction (Stanley \& Szabó 2000).

For example, in (10) below the domains of bottles and corners intuitively co-vary with the quantifier every room, i.e., the natural reading of this sentence is that for every room, every bottle in that room is in the corner of that room.

(10) In every room, every bottle is in the corner. (Stanley 2005: 212)

On Stanley and Szabó's proposed analysis of domain restriction, the covarying reading of these determiner phrases is explained as follows. The nouns bottle and corner are associated with variables that serve to restrict their domains. However, these “domain variables" are bindable by higher quantifiers, so in the context of (10), the variables are bound by every room, viz.,

(11) In every room $x$, every bottle [in $x$ ] is in the corner [of $x$ ]. 
Fara suggests that by adopting Stanley and Szabó's analysis, one can explain the availability of a co-varying reading of the determiner phrase in (9) in a way consistent with the generalisation where ' $\emptyset_{\text {the }}$ ': Qua being a count noun, the name John is syntactically associated with a domain variable that is bound by a higher quantifier, and this is what permits the determiner phrase the John to co-vary with the quantifier every race. Hence, the relevant syntactic structure of (9) is that given by (12). ${ }^{3}$

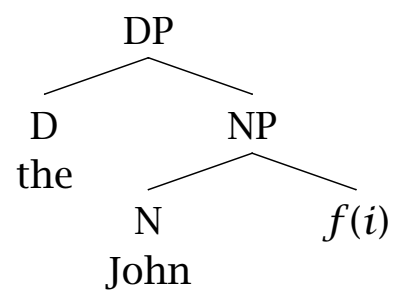

(13)

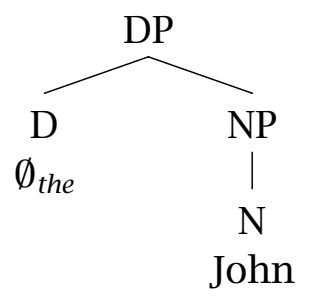

By contrast, the structure of the DP in (2) where John does not have a covarying reading is given by (13), cf. Fara 2015a: 369 .

Assuming that this is the correct syntactic analysis of the sentences in (2) and (9), Fara's descriptive generalization 'where $\emptyset_{\text {the }}$ ' now correctly predicts that only (9) has a co-varying reading. The explanation is that for the co-varying reading to arise, a domain variable associated with the nominal phrase must be bound by a higher quantifier, but once the name has a syntactic sister, the definite article must then be pronounced. In other words, co-varying readings only arise when the name has a bound domain variable as its syntactic sister.

This seems both a simple and elegant explanation of the contrast between (2) and (9) as well as (2) and (3). 4

3 According to Stanley \& Szabó 2000, a domain variable is a complex $f(i)$ where $f$ is a contextually determined function from individuals to sets and $i$ is assigned an individual in context. There are important reasons why the domain variable must have this complex structure, but these reasons won't matter for the discussion here, so see Stanley 2002: 127-128 for discussion.

4 It deserves mentioning here that the syntactic assumptions underlying Stanley and Szabó's account are controversial. For example, Elbourne 2008 argues that if the domain variable 
A problem for Predicativism not solved by Predicativism

Nevertheless, I believe that there is a fundamental problem with Fara's proposed explanation. To see this problem, we need to consider, in a bit more detail, the theory on which Fara's explanation is predicated, namely Stanley and Szabó's theory of domain restriction or, rather, nominal restriction.

It is widely agreed that quantificational determiner phrases are contextsensitive. For example, the domain of beers in (14) is rarely (if ever) understood as including every beer in the universe.

(14) Every beer is in the fridge.

Note that this is a perfectly general observation that extends to any other quantifier phrase in English. So, the generality of the observation intuitively motivates the assumption that quantifier phrases are conventionally associated with some kind of restriction. One key question, however, is whether such a restriction is syntactically manifested, e.g., as a domain variable at LF. And, if so, where.

In their paper, Stanley and Szabó argue for two separate claims, namely (a) that domain restriction is conventionally encoded as a covert element at LF (as a domain variable), and (b) that this covert element is associated with the nominal phrase - not the determiner. Moreover, Stanley argues in a subsequent paper that this variable must inhabit its own terminal node, $\mathrm{cf}$. Stanley 2005: fn.15. That is, it must be the syntactic sister of the associated nominal phrase. In other words, the LF of a canonical determiner phrase with a quantifier is roughly (15a).

(15) every/some/no F

is assumed to be associated with the nominal (either as cohabiting the node containing the nominal or as its syntactic sister), the account overgenerates and predicts unattested bound readings of certain kinds of expressions. Moreover Elbourne demonstrates that if the relevant variable is instead associated with the determiner, as in, for example, von Fintel 1994 and more recently Schwarz 2012, these incorrect predictions can be avoided, cf. Elbourne 2008: 101-105 for details. If correct, this is of course particularly problematic for Fara as her solution depends crucially on the assumption that the domain variable is the syntactic sister of the nominal. Moreover, it is argued in Collins 2007 that there is no convincing syntactic evidence in favor of the assumption that there is an unpronounced and bindable domain variable at LF. In particular, Collins maintains that the examples offered by Stanley and Szabó are not examples that can plausibly be understood as cases involving syntactic binding yet this is what is needed in order to support the assumption of a covert constituent at LF. For more discussion, see Collins 2007: 831-834. 
A. J. Schoubye

a.

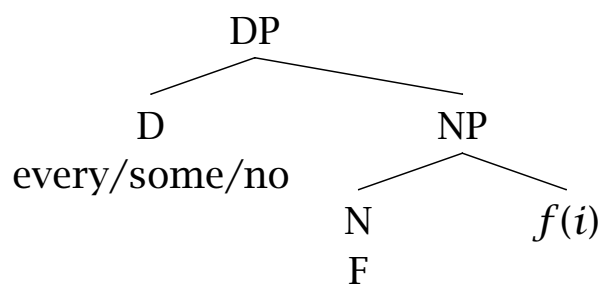

One of Stanley and Szabó's principal arguments in favor of this view is precisely that quantifier phrases have "bound" (or co-varying) readings when in the scope of other quantifier phrases. This fact, they argue, suggest that nominal phrases have associated domain variables that are syntactically bindable. If they did not, it would be quite difficult to explain how co-varying readings arise. Moreover, by assuming that domain variables are assigned semantic values by context, when occurring free, one can thereby explain domain restriction more generally, i.e., why the natural interpretation of the determiner phrase (14) is with a restricted domain of beers. ${ }^{5}$

It is, however, important to emphasize that on Stanley and Szabó's view, nominal phrases are associated with domain variables quite generally. The view is not that these variables simply spring into existence whenever a nominal phrase occurs in the scope of a higher quantifier (and has a bound reading).

This is important, because if nominals are conventionally associated with domain variables, this causes a problem for Fara's proposed generalization. Consider again the syntactic representation in (13) above. If Stanley and Szabó's theory is correct, this structure does not accurately represent the logical form of the DP, because the domain variable associated with the nominal John is missing. Rather, if The-Predicativism is combined with the Stanley-Szabó analysis of domain restriction, the LF for a sentence such as (1) would be (1a).

\section{(1) John is a philosopher.}

5 The argument that bound readings of sentences justifies positing bindable elements at the level of LF has also been contested, see e.g., Cappelen \& Lepore 2002 and Recanati 2007. 
A problem for Predicativism not solved by Predicativism

a.

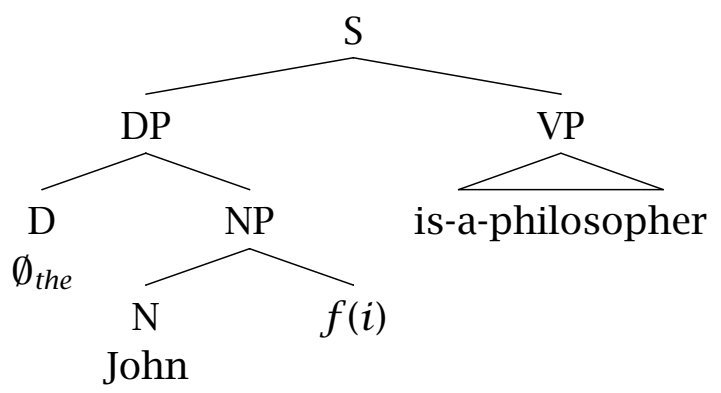

But if this is the LF for (1), the generalization in 'Where $\emptyset_{\text {the }}$ ' makes the wrong prediction. The determiner does not have a (bare) name as its structural sister, so the generalization predicts that 'the' in (1) should be pronounced.

Moreover, this is a completely general problem. Once it is assumed that nominal phrases are conventionally associated with a syntactic sister node containing a domain variable, Fara's generalization will consistently make the wrong prediction for bare singular names in argument position of a predicate. This is quite clearly a devastating result.

There are a couple of responses on behalf of Fara that might seem natural here. For example, why not just assume that the domain variables associated with names are only present at LF when they are bound? One reason to not assume this is that these domain variables are needed in contexts where the variables are not bound. Consider, for example, (16) and (17) below.

(16) Every Louise failed the exam.

(17) No Louise failed the exam.

Suppose that there are three individuals in my class called Louise. If they all failed the exam, I could now truthfully assert (16). Similarly, if they all passed the exam, I could now truthfully assert (17). But since there are more than three people called Louise in the world, domain restriction is needed to explain these intuitive truth value judgments. So, the domain variables are needed for these cases.

Another reason that the response fails is that it undermines the explanation that the nominal restriction theory is supposed to provide. Consider again the contrast between (2) and (9). The explanation of this contrast is that in (9) the name is associated with a bound domain variable, whereas in (2) it is not associated with any such variable. But, given this explanation, it seems perfectly reasonable to ask what justifies the assumption that there is a variable in (9) but not in (2)? There is no immediately satisfactory answer to 
this question, because the variable is assumed to be present in (9) exclusively for the purpose of explaining this contrast. But without an independent justification for the presence of the variable in (9), and the absence of a variable in (2), this explanation is entirely stipulative.

Another potential response is to maintain that domain restrictions are strictly optional. So, if the speaker intends the bound reading of (10), she must include the covert PP in $x$ as sister to the nominal bottle. By contrast, if the speaker merely intends to refer to a single individual, as in (1), no domain restriction is needed and consequently the definite article must remain unpronounced. ${ }^{6}$

The main problem with this suggestion is that it leaves it unclear why it seems clearly inappropriate (bordering on ungrammatical) to utter things such as The Bob cried or The Louise has blond hair. After all, if domain restrictions are optional, there can be no syntactic prohibition against adding e.g., a vacuous PP. And from a semantic point of view this would be equivalent to having no domain restriction. In other words, it should be possible to assert that Bob cried by uttering the sentence the Bob cried. Now, there are probably good pragmatic reasons against employing vacuous domain restrictions, but it seems implausible that the anomaly associated with these kinds of sentences can be explained on purely pragmatic grounds. In addition, regardless of whether domain restrictions are optional or not, it remains unclear why, on Fara's view, descriptions such as the Bob or the Louise cannot be used attributively (as long as a suitable, and non-vacuous, restrictor is intended by the speaker). After all, it is perfectly possible to use descriptions such as the table and literally mean the table in this room (or something along such lines). But given this, it should be possible to use e.g., the Bob this way too, but it is not.

Finally, Fara might argue that her proposed generalization simply needs to be amended. However, the question then is how? If nominal phrases are consistently associated with domain variables, then names always have a

6 Paul Elbourne (pc.) pointed out that even in cases such as (1) domain restriction appears to be needed. The description ' $\emptyset_{\text {the }}$ John' in (1) presupposes that a unique individual satisfies the predicate John, so this description will succeed in referring only if the domain is appropriately restricted. This seems intuitively right to me, but I should note that Fara explicitly rejects domain restrictions as a way of explaining how incomplete descriptions succeed in referring, cf. Fara 2015c: 99-100. Fara does assume that incomplete descriptions are referential expressions (because she argues extensively for the thesis that incomplete descriptions are rigid). However, she never addresses the problem of how incomplete descriptions come to refer in the first place. For discussion of this issue, see Schoubye 2016. 
A problem for Predicativism not solved by Predicativism

syntactic sister node at LF, regardless of whether they occur as bare singulars in the surface structure. So, it now becomes considerably more difficult to formulate a generalization that is descriptively accurate, let alone genuinely predictive.

Also, notice that when Fara initially proposes the Where $\emptyset_{\text {the }}$-generalization, she explicitly eschews a merely "disjunctive" definition. The reason is that Fara thinks that in order for this generalization to be predictive, i.e., to genuinely account for the distributional facts about names and count nouns, it must be sufficiently simple and systematic. ${ }^{7}$ In conclusion, the key question is whether there is any plausible way of amending Fara's generalization such that it is descriptively accurate while also being genuinely predictive. This is far from clear.

In short, Fara has not provided a satisfactory explanation of the contrast noted by Hawthorne and Manley. The existence of this contrast thus remains a problem, because there should not be a contrast if The-Predicativism were true.

Finally, it is worth nothing that the contrast is straightforwardly explained by accounts that distinguish between referential names and predicative names - see e.g., Leckie 2013 and Schoubye forthcoming. On these accounts, the name John in (2) is simply a directly referential and rigid singular term which explains why it cannot be interpreted as co-varying even when embedded in the scope of various operators such as nominal quantifiers. By contrast, John in (9) is a predicate, and so assuming that Stanley and Szabó's analysis is correct (or any other analysis that posits a bindable element with respect to DPs), the co-varying reading of the description is a simple consequence of the domain variable associated with the John being bound.

\section{References}

Cappelen, Herman \& Ernest Lepore. 2002. Indexicality, binding, anaphora, and a priori truth. Analysis 62(4). 271-281. http://dx.doi.org/10.1111/14678284.00367.

7 For example, Fara explicitly states that the generalization is supposed to account for the syntactic facts: "We can also make predictive generalizations about the syntactic differences between names and other count nouns. Sloat (1969) has already provided such a generalization. We will provide a slight amendment to Sloat's generalization about the distribution of determiners with names and other count nouns. Then we will formulate a syntactic hypothesis that accounts for it." (Fara 2015c: 81, my emphasis). 
Collins, John. 2007. Syntax, more or less. Mind 116(464). 805-850. http: //dx.doi.org/10.1093/mind/fzm805.

Elbourne, Paul. 2005. Situations and individuals. Cambridge, Massachusetts: MIT Press.

Elbourne, Paul. 2008. The Argument From Binding. Philosophical Perspectives 22. 89-110. http://dx.doi.org/10.1111/j.1520-8583.2008.00142.x.

Fara, Delia Graff. 2011. You can call me ‘stupid', ... just don’t call me stupid. Analysis 71(3). 492-501. http://dx.doi.org/10.1093/analys/anro45.

Fara, Delia Graff. 2015a. A problem for predicativism solved by predicativism. Analysis 75(3). 362-371. http://dx.doi.org/10.1093/analys/anv042.

Fara, Delia Graff. 2015b. "Literal” uses of proper names. In Andrea Bianchi (ed.), On Reference, chap. 12, 251-279. Oxford: Oxford University Press.

Fara, Delia Graff. 2015c. Names are predicates. Philosophical Review 124(1). 59-117. http://dx.doi.org/10.1215/o0318108-281266o.

von Fintel, Kai. 1994. Restrictions on quantifier domains. University of Massachusetts, Amherst dissertation.

Geurts, Bart. 1997. Good news about the description theory of names. Journal of Semantics 14. 319-348. http://dx.doi.org/10.1093/jos/14.4.319.

Hawthorne, John \& David Manley. 2012. The reference book. Oxford: Oxford University Press.

Izumi, Yu. 2013. The semantics of proper names and other bare nominals. University of Maryland, College Park dissertation.

Leckie, Gail. 2013. The double life of names. Philosophical Studies 165. 1139116o. http://dx.doi.org/10.1007/s11098-012-0008-3.

Matushansky, Ora. 2006. Why Rose is the Rose: On the use of definite articles in proper names. In Olivier Bonami \& Patricia Cabredo Hofherr (eds.), Empirical issues in syntax and semantics, vol. 6, 285-307.

Matushansky, Ora. 2008. On the linguistic complexity of proper names. Linguistics and Philosophy 21. 573-627. http://dx.doi.org/10.1007/s10988008-9050-1.

Recanati, François. 2007. It is raining (somewhere). Linguistics and Philosophy 30(1). 123-146. http://dx.doi.org/10.1007/s10988-006-9007-1.

Schoubye, Anders J. 2016. The predicative predicament. ms. http://www. schoubye.org/papers/TPP.pdf.

Schoubye, Anders J. Forthcoming. Type-ambiguous names. Forthcoming in Mind. 
A problem for Predicativism not solved by Predicativism

Schwarz, Florian. 2012. Situation pronouns in determiner phrases. Natural Language Semantics 20(4). 431-475. http://dx.doi.org/10.1007/s11050012-9086-1.

Stanley, Jason. 2002. Nominal restriction. In Gerhard Preyer \& Georg Peter (eds.), Logical form and language, 365-388. Oxford: Clarendon Press.

Stanley, Jason. 2005. Semantics in context. In Gerhard Preyer \& Georg Peter (eds.), Contextualism in philosophy: Knowledge, meaning, and truth, chap. 9, 221-255. Oxford University Press.

Stanley, Jason \& Zoltan Gendler Szabó. 2000. On quantifier domain restriction. Mind and Language 15. 219-261. http://dx.doi.org/10.1111/14680017.00130.

Anders J. Schoubye

Department of Philosophy

University of Edinburgh

Dugald Stewart Building

3 Charles Street

Edinburgh, EH11 1RJ

United Kingdom

anders.schoubye@ed.ac.uk 